\title{
FACTORS AFFECTING LIVER LIPID CONTENT IN PYRIDOXINE-DEFICIENT RATS. I. DIETARY PROTEIN LEVELS
}

\author{
Kazuhiko SuzukI, Teiji Nakamura, Masataka FuJITA, \\ Tamako IwAmI, Midori ABE, and Mitsuko OKADA ${ }^{1}$ \\ Department of Nutrition, School of Medicine, Tokushima University, Tokushima
}

(Received February 9, 1976)

\begin{abstract}
Summary Effects of choline fortification and various dietary protein levels on liver lipid content in pyridoxine-deficient rats were studied. Choline fortification did not prevent the accumulation of liver lipids in pyridoxine-deficient rats. Considerable accumulation of liver lipids was observed in the $70 \%$ casein pyridoxine-deprived group. Reducing the protein level in the diet decreased the extent of lipid accumulation. A highly negative correlation was found between liver lipid content and liver GPT activity, indicating that the fatty infiltration of the liver may be intimately related to the pyridoxine deficiency state. The time course of fatty liver induction upon feeding of a $70 \%$ casein pyridoxine-deficient diet was also studied. The liver lipid content increased gradually and reached the highest value by the third week with a concomitant decrease in food intake. Effect of change of dietary compositions on fatty liver caused by $70 \%$ casein pyridoxine-free diet was examined. Feeding of a $70 \%$ casein pyridoxine-supplemented diet or a $20 \%$ casein pyridoxine-free diet caused decreases in the liver lipids.
\end{abstract}

Vitamin $\mathbf{B}_{6}$ is known to play some roles in lipid metabolism. The extent of conversion of linoleate to arachidonate is much greater in pyridoxine-supplemented than in pyridoxine-deficient animals $(1,2)$. Pyridoxal phosphate is involved in the synthesis of sphingosine (3). Feeding of a pyridoxine-deficient diet reduces the amount of body fat in rat $(4,5)$. The liver lipid content has been reported to be lowered $(6,7)$, or unchanged in pyridoxine deficiency $(5)$. Deprivation of pyridoxine in the Rhesus monkey, caused arteriosclerosis and fatty metamorphosis (9). AVERY and LUPIEN (10) reported that the incorporation of ${ }^{14} \mathrm{C}$-acetate into liver cholesterol was accerelated in pyridoxine-deficient rats owing to the stimulated conjugation of cholic acid with glycine and taurine. Our previous study (11) has shown that feeding of high protein diet to pyridoxine-

1 鈴木和彦, 中村丁次, 藤田正隆, 岩見玉子, 阿部ミドリ, 岡田美津子 
deficient rats causes an accumulation of triglyceride and cholesterol in the liver. In view of the early report of HALLIDAY ( 8 ) who found that choline supplementation prevented the fatty liver caused by pyridoxine deficiency, we wanted to find out if choline actually acts as a lipotropic factor in the fatty liver induced by $70 \%$ casein pyridoxine-deficient diet. We also studied factors affecting liver lipid content in pyridoxine-deficient rats especially in relation to the dietary protein content.

\section{MATERIALS AND METHODS}

Male rats of Wistar strain weighing about $45 \mathrm{~g}$ were purchased from Nishin Kikai company. All rats were maintained on $20 \%$ casein basal diet for 2 to 3 days before receiving the experimental diet. Rats weighing 50 to $60 \mathrm{~g}$ were used for the present experiments. The rats were kept in screenwire cages. Water and experimental diet were given ad libitum throughout the experimental periods to the pyridoxine free group. Food consumption of deficient rats was measured daily and the equal amounts of food containing pyridoxine were given to the control animals. The experimental diet contained 10 to $70 \%$ vitamin-free casein, 7 to $67 \%$ corn starch, $10 \%$ sucrose, $8 \%$ cod liver oil-soy bean oil mixture $(1: 4)$, $4 \%$ salt mixture, $1 \%$ vitamin mixture and $0.2 \%$ choline chloride. Variation in protein contents was made at the expense of corn starch as described previously(11).

Extraction of liver lipids. $\quad$ Lipid extraction was carried out essentially by the method of Folch et al. (12). The liver lipids were extracted from $2 \mathrm{ml}$ of $20 \%$ liver homogenate. The total liver lipid was estimated gravimetrically as previously described (11).

Measurement of enzyme activity. Rats were killed by decapitation after 3 weeks on various diets. Livers were removed and a $2 \%$ homogenate was prepared in cold $0.025 \mathrm{M}$ potassium phosphate buffer, $\mathrm{pH}$ 7.4. Alanine aminotransferase (GPT) [EC 2.6.1.2] activity was assayed by a colorimetric method using 2,4-dinitrophenylhydrazine (13). Protein concentration was determined by the biuret reaction (14). The enzyme activity was expressed as $\mu$ moles pyruvate formed per minute per mg protein.

Experiment 1: The effect of choline fortification on liver lipid content in pyridoxine-deficient rats. Rats were divided into 2 groups of 6 animals each. Both groups were fed $70 \%$ casein pyridoxine-free diet ad libitum, but the dietary choline contents were different in two groups. One diet contained standard amount $(2 \mathrm{~g} / \mathrm{kg}$ diet $)$ and another diet contained twice the standard amount $(4 \mathrm{~g} / \mathrm{kg}$ diet). After 3 weeks, the liver lipids were determined.

Experiment 2: The effect of dietary protein levels on liver lipid content in pyridoxine-deficient rats. Rats were divided into 8 groups, each consisting of 5 or 6 animals. Diets containing 10,30, 50 or $70 \%$ casein with or without pyridoxine were used for the experiment. After 3 weeks, rats of all groups were killed, 
and liver lipids, GPT activity and organ weights were determined.

Experiment 3: Correlation between liver lipid content and liver GPT activity. Sixteen rats were fed $70 \%$ casein pyridoxine-free diet for 19 days. Both liver lipid and GPT activity were then measured as described above.

Experiment 4: The time course in the development of fatty liver in pyridoxinedeficient rats. Rats were divided into 7 groups, each consisting of 5 animals. One group was killed before receiving experimental diet and the liver lipid content was taken as the control 0 week sample. The remaining 6 groups were fed $70 \%$ casein diet with or without pyridoxine. The rats were killed at one week intervals and the liver lipids were determined.

Experiment 5: The effect of dietary change on liver lipid content in pyridoxinedeficient rats. Twenty-four rats were fed $70 \%$ casein pyridoxine-free diet for 19 days and then divided into 4 groups. The first group was killed immediately. The feeding of the second group with the same diet was continued. The 3rd group was fed a $70 \%$ casein pyridoxine-containing diet and the 4 th group was supplied with a $20 \%$ casein pyridoxine-free diet. Both the 3 rd and 4 th groups were pair-fed with the 2 nd group for additional 2 days. On the 21 st day, all groups were sacrificed and the liver lipid contents were determined.

\section{RESULTS}

The effect of choline fortification on liver lipid content in pyridoxine-deficient rats

Choline is known to be a lipotropic factor. We examined whether or not choline acts as a lipotropic factor in the fatty liver induced by high protein pyridoxine-deficient diet. After rats were fed choline-rich, pyridoxine-deficient diet for 3 weeks, liver lipid contents were determined. As shown in Table 1, the supplementation of excess choline failed to decrease the liver lipid contents. Thus, choline does not appear to act as a lipotropic factor in our condition of fatty liver induction.

Table 1. The effect of choline fortification on liver lipids content in pyridoxine-deficient rats.

\begin{tabular}{cc}
\hline Diet & Liver lipids $(\%)$ \\
\hline $70 \%$ casein, pyridoxine $(-)$, choline $(++)$ & $7.18 \pm 1.13$ \\
$70 \%$ casein, pyridoxine $(-)$, choline $(+)$ & $7.22 \pm 0.67$ \\
\hline
\end{tabular}

$(+)$ and $(++)$ contained $2 \mathrm{~g} / \mathrm{kg}$ diet and $4 \mathrm{~g} / \mathrm{kg}$ diet of choline, respectively.

The effect of dietary protein levels on liver lipid content in pyridoxine-deficient rats The effect of dietary protein levels on food intake, weight gain, and liver and kidney weights is shown in Fig. 1. As indicated in Fig. 1a, the total amounts of food consumption for the experimental period ( 3 weeks) were maximal in the group fed a $30 \%$ protein diet, and gradually decreased with increasing dietary protein contents. Animals fed $70 \%$ casein consumed only about $2 / 3$ of the amount 


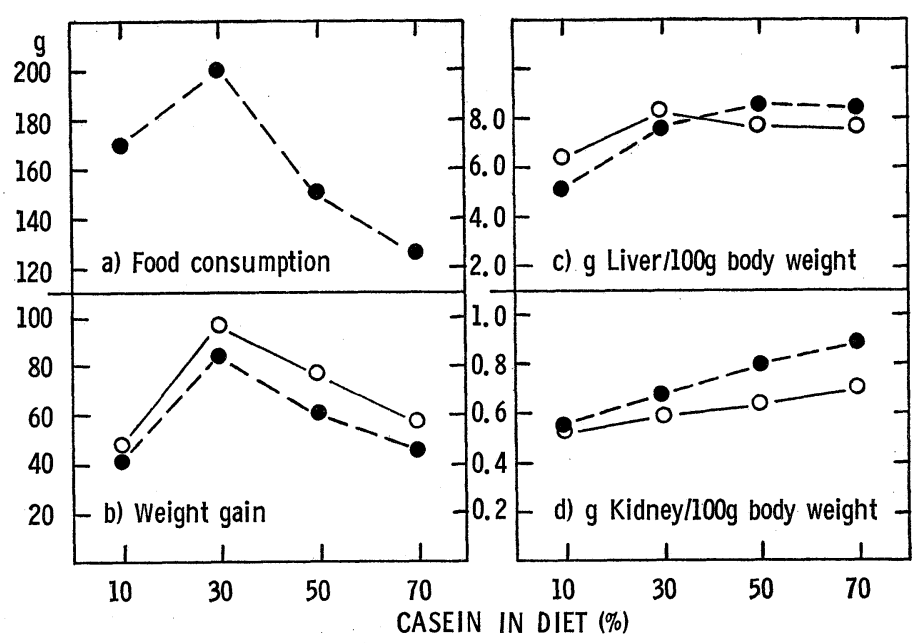

Fig. 1. The effect of dietary protein levels on food consumption, weight gain, and relative liver and kidney weights. ---@, pyridoxine-deficient rats; $\bigcirc-\bigcirc$, pair-fed control rats. Data were presented as the mean of 5 or 6 animals.

consumed by the $30 \%$ group. Figure $1 \mathrm{~b}$ shows weight gain of the animals fed various diets during the experimental period. The weight gains of pair-fed animals were very similar to those of the deficient animals, but the weight gains in the deficient group were slightly lower than those in the control group at all protein levels. The weight gain curves generally parallel the food consumption curve, but the food efficiency of the $10 \%$ casein diet appears to be considerably lower than that of higher casein diets. Dermal and hair dryness symptoms were also found in the 30,50 and $70 \%$ casein deficient groups. Relative enlargement of the liver was observed in the 50 and $70 \%$ casein deficient groups (Fig. 1c). On the other hand, in the 10 and $30 \%$ deficient groups, the relative liver weights were lower than those in pair-fed control rats. There seems to be a critical point between 30 and $50 \%$ casein levels that characterizes the liver proliferation in pyridoxine-deficient rats. The kidney weights showed different relationships from those of liver: the relative kidney weights increased linearly with increasing dietary casein contents (Fig. 1d). Hypertrophy of kidney was observed in 30\%,50\% and $70 \%$ casein deficient groups. Liver lipids of rats fed diets containing different levels of protein are shown in Fig. 2a. In the deficient groups, higher lipid contents were observed in the livers of rats fed $50 \%$ or $70 \%$ casein diet. Pair-feeding of pyridoxinesupplemented control diets did not induce elevation of liver lipid contents at all protein levels. We assayed the liver GPT activity as a criterion of the degree of pyridoxine deficiency (Fig. 2b). The relative GPT activity (the ratio of GPT activity in the deficient animals to that in the pair-fed animals) decreased with increasing diet protein levels, indicating that the $70 \%$ casein deficient group suffered from the most severe pyridoxine deficiency. 


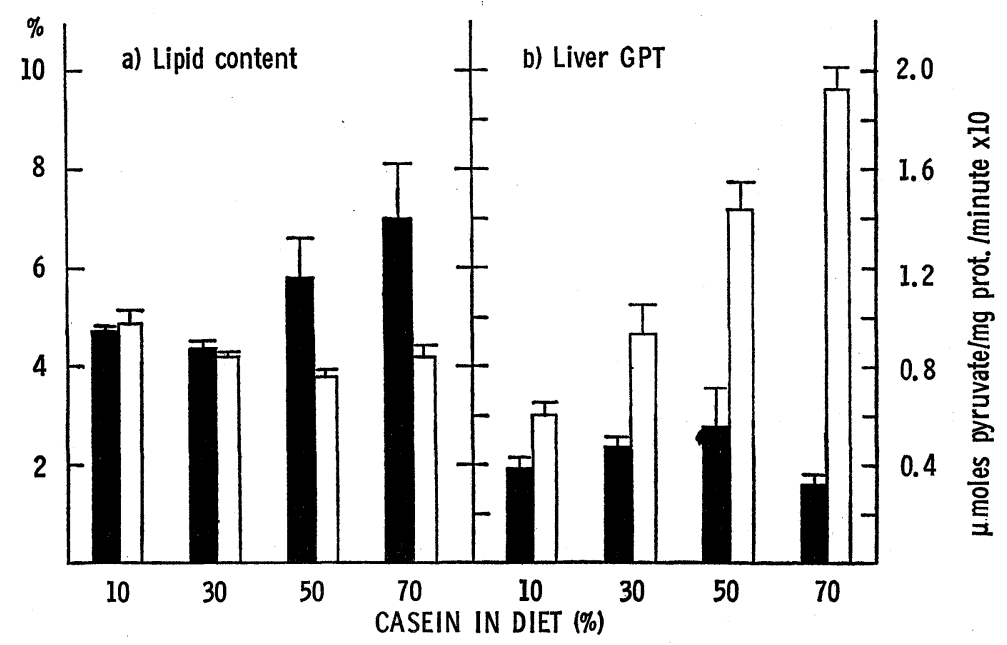

Fig. 2. The effect of dietary protein levels on liver lipid content and liver GPT activity. Closed bars indicate pyridoxine-deficient rats and opened bars indicate pair-fed control rats. Vertical lines represent standard error of mean.

\section{Correlation between liver lipid content and liver GPT activity}

After rats were fed pyridoxine-deficient diet for 19 days, both GPT activity and lipid content were measured. To see if liver lipid content is somehow related

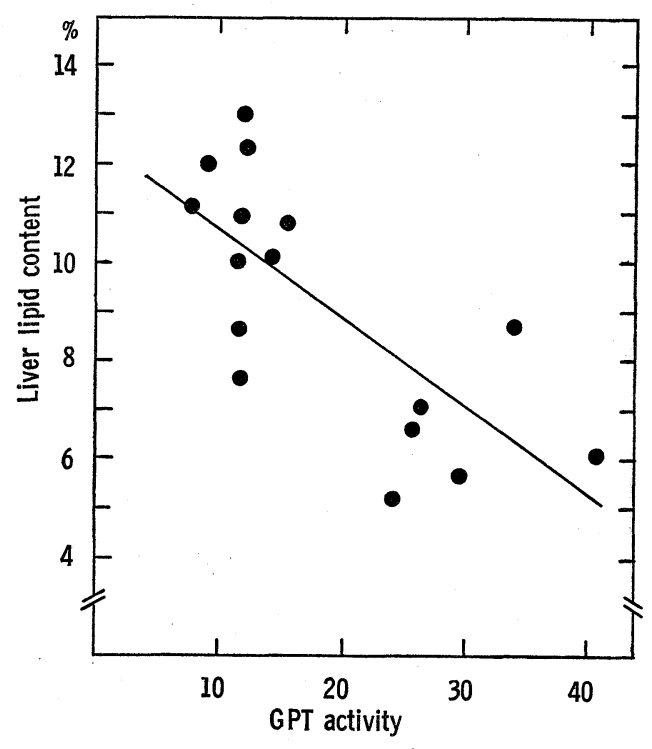

$\mu \mathrm{moles} / \mathrm{mg}$ protein/minute $\times 300$

Fig. 3. Correlation between liver lipid content and liver GPT activity in pyridoxine-deficient rats. 
to the pyridoxine-deficient state, we analysed the statistical correlation between liver lipid content and GPT activity. The regression line, $Y=-0.178 X+12.5$ ( $r=-0.7377, P<0.05$ ), indicates that liver lipid accumulation in pyridoxinedeficient rats is intimately related to the level of liver GPT activity, and therefore to the degree of pyridoxine deficiency.

\section{The time course in the development of fatty liver in pyridoxine-deficient rats}

The time course in the change of liver lipids with a $70 \%$ casein deficient diet and control diet were investigated for a 3 week period. As seen in Fig. 4, the liver lipid of the deficient rat started to rise within 1 week, and was increased to 2.3 times the value of the pair-fed control at 3 weeks. Food consumption gradu-

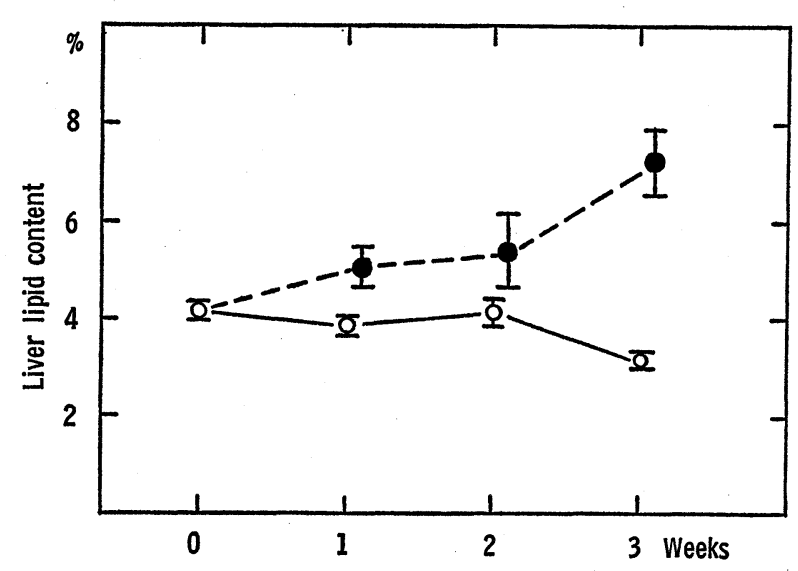

Fig. 4. The time course in the development of fatty liver in pyridoxine-deficient rat. pyridoxine-deficient rats; $\bigcirc-\bigcirc$ pair-fed control rats. Vertical lines represent standard error of mean.

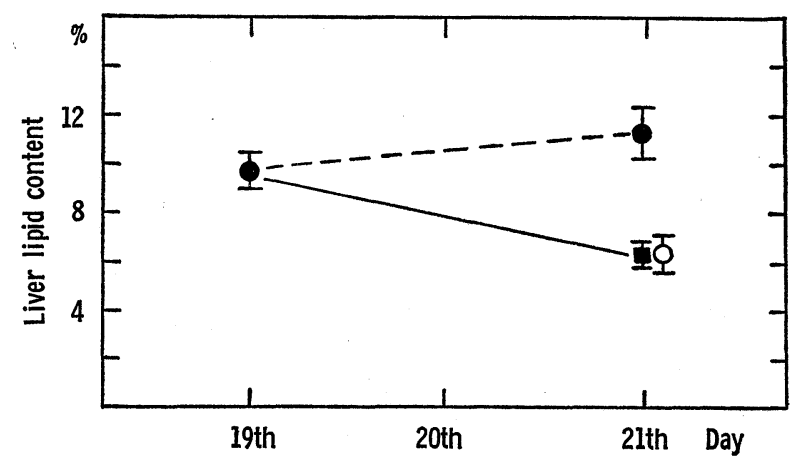

Fig. 5. The effect of dietary change on liver lipid content in pyridoxine-deficient rat. $70 \%$ pyridoxine-free diet, (⿴) $20 \%$ pyridoxine-free diet, ( $\bigcirc)$ (0) pyridoxine-supplemented diet. 
ally decreased during this period. One should notice that the normal liver lipid content was maintained in the pair-fed control rats.

The effect of change of dietary compositions on the liver lipid contents in pyridoxinedeficient rats

The effect of change of dietary compositions on the fatty liver previously induced by the $70 \%$ casein pyridoxine-deficient diet was studied. Rats were fed $20 \%$ casein pyridoxine-free diet or $70 \%$ casein pyridoxine-supplemented diet for 2 days after being fed $70 \%$ casein pyridoxine-free diet for 19 days. As shown in Fig. 5, the liver lipids were decreased in both groups, while control group, fed $70 \%$ casein pyridoxine-free diet continuously, showed further increase. Although the liver lipid content was decreased, in $70 \%$ casein pyridoxine-supplemented group significant enlargement of liver was observed.

\section{DISCUSSION}

Feeding of pyridoxine-deficient diet to rats usually caused significant decrease in the food intake. Since the distinction between the primary effect of pyridoxine deficiency and the secondary effect of reduced food intake (15) is very important, pair-fed animals were used as controls in the present study. Hypocholesterogenesis seen in fasting animals (16) was not observed in pyridoxine-deficient rats as estimated by the incorporation of ${ }^{14} \mathrm{C}$-acetate into liver cholesterol in vivo and in vitro (17). In the histological study, fatty infiltration of the liver in pyridoxinedeficient animals showed a centrolobular distribution (18), whereas that in fasting animals was peripheral in character. Fatty livers resulting from pyridoxine or choline deficiency are histologically quite similar, but choline failed to act as lipotropic agent in pyridoxine-deficient rats. Feeding of high-protein diet plus severity of pyridoxine deficiency was found to be essential for induction of fatty liver in our case. Since the fatty liver was alleviated with a $20 \%$ casein pyridoxinedeficient diet for only 2 days, pyridoxine deficiency may not be directly responsible for the accumulation of liver lipids. Increased intake of carbohydrate and the attendant change in the hormonal conditions may be contributing factors. The hepatic enlargement does not seem to be related to the induction of fatty liver, because the fat deposition was decreased by administration of pyridoxine for 2 days when liver weights still remained at high levels. At present, we can only say that the fatty infiltration of liver is due to a disturbance of homeostasis in the regulatory system of hepatic lipid metabolism under severe pyridoxine deficiency. The first report of fatty liver induction by pyridoxine deficiency appeared in $1938(8)$, but subsequent studies of other investigators $(6,7,19)$ failed to confirm the initial observation. Audet and LuPIEN (19) reported a lower content in the liver triglyceride after feeding $22 \%$ casein pyridoxine-deficient diet for 8 weeks. Indeed our previous study (11) showed that feeding of $10 \%$ casein pyridoxine- 
deficient diet for 4 weeks caused lowering on liver lipid content. Thus, feeding of high protein pyridoxine-deficient diet seems essential for reproducible induction of fatty liver. Furthermore, we have obtained an evidence indicating that the fatty liver is more readily induced in the male rats than in the females. Activities of some pyridoxal-requiring enzymes, such as serine dehydratase, ornithine transaminase and GPT, were higher in females than those in males in both control and pyridoxine-deficient rats (20). LeFAUCONNIER et al. (21) showed that the hepatic level of pyridoxal phosphate was higher in females than that in males. This sex difference should be contrasted with that in the ethionine-induced fatty liver where female rats are more prove to fatty liver induction than males (22).

\section{REFERENCES}

1) Witten, P. W. and Holman, R. T., Arch. Biochem. Biophys., 41, 266 (1952).

2) WAKIL, S., J. Lipid Res., 2, 1 (1961).

3) Braun, P. E. and Snell, E. E., Proc. Nat. Acad. Sci., 58, 298 (1967).

4) McHenry, E. W. and Gavin, G., J. Biol. Chem., 138, 471 (1941).

5) Desikachar, H. S. R. and McHenry, E. W., Biochem. J., 56, 544 (1954).

6) Carter, C. W. and Phizackerley, J. R., Biochem. J., 49, 227 (1951).

7) Swell, L., Law, M. D., Schools, P. E., Jr., and Treadwell, C. R., J. Nutr., 74, 148 (1961).

8) Halliday, N., J. Nutr., 16, 285 (1938).

9) Rinehart, J. F. and Greenberg, L. D., Am. J. Clin. Nutr., 4, 318 (1956).

10) Avery, M. D. and Lupien, P. J., Can. J. Biochem., 49, 1026 (1971).

11) OKadA, M. and OcHI, A., J. Biochem., 70, 581 (1971).

12) Folch, J., Lees, M., and SloAne Stanley, G. H., J. Biol. Chem., 226, 497 (1957).

13) Rosen, F., Robert, N. R., and Nichol, C. A., J. Biol. Chem., 234, 476 (1959).

14) Gornall, A. G., Bardawill, C. S., and David, M. M., J. Biol. Chem., 177, 751 (1949).

15) Huber, A. M., Gershoff, S. N., and Hegsted, D. M., J. Nutr., 82, 371 (1964).

16) Bucher, N. L. R., Overath, P., and Lynen, F., Biochim. Biophys. Acta, 40, 491 (1960).

17) Iwami, T., Suzuki, K., Gomikawa, S., and Okada, M., Vitamins (in Japanese), 49, 321 (1975).

18) OKaDA, M. and OCHI, A., Vitamins (in Japanese), 43, 241 (1971).

19) Audet, A. and Lupien, P. J., J. Nutr., 104, 91 (1974).

20) Okada, M., Deguchi, K., Nomura, M., Futo, Y., and Suzuki, K., Vitamins (in Japanese), 48, 320 (1974).

21) Lefauconnier, J. M., Portemer, C., DeBilly, G., and Chatagner, F., Horm. Metab. Res., 5, 372 (1973).

22) Farber, E., Simpson, M. V., and TARver, H., J. Biol. Chem., 182, 91 (1950). 